\title{
OPTIMALISASI PENGEMBANGAN KAWASAN AGROPOLITAN MALALO MELALUI PEMETAAN KOMODITAS UNGGULAN
}

\author{
Muhammad Anshar ${ }^{1}$, Irsyadi Siradjuddin ${ }^{1}$, Amirin Kusmiran ${ }^{2}$ \\ ${ }^{1}$ Prodi Teknik Perencanaan Wilayah dan Kota \\ Fakultas Sains dan Teknologi UIN Alauddin Makassar \\ Jl. Sultan Alauddin No. 63, Gowa, Sulawesi Selatan. 92113 \\ *E-mail: muhammad.anshar@uin-alauddin.ac.id \\ ${ }^{2}$ Prodi Fisika \\ Fakultas Sains dan Teknologi UIN Alauddin Makassar \\ Jl. Sultan Alauddin No. 63, Gowa, Sulawesi Selatan. 92113
}

\begin{abstract}
Abstrak: Pengembangan kawasan agropolitan Malalo saat ini belum optimal karena perencanaan pengembangan wilayah berbasis potensi komoditas yang tidak terkait sehingga komoditas unggulan yang dikembangkan tidak tepat sasaran. Oleh karena itu, komoditas pertanian yang menjadi komoditas basis yang dijadikan komoditas unggulan perlu dikenali. Pemetaan komoditas di kawasan agropolitan Malolo dilakukan dengan menggunakan software ArcGIS dan dianalisis secara deskriptif kualitatif dan kuantitatif. Hasil penelitian menunjukkan bahwa komoditas pertanian yang menjadi komoditas pokok di kawasan agropolitan Malolo adalah padi, jagung, kacang hijau, ubi kayu, dan ubi jalar. Dari komoditas tersebut, komoditas unggulan yang dapat dijadikan komoditas unggulan di kawasan agropolitan Malolo adalah komoditas jagung yang tersebar di desa-desa dan keluarga, yaitu Towata, Barugaya, Timbuseng, dan Massamaturu.
\end{abstract}

Kata Kunci: komoditas dasar, komoditas unggulan, perkembangan

\section{PENDAHULUAN}

$\mathbf{P}$ erencanaan pengembangan wilayah yang berbasis pada potensi komoditas perkebunan unggulan perlu diketahui melalui pemetaan potensinya (Baladina et al., 2013; Setianto \& Susilowati, 2014). Kawasan agropolitan dirancang dan dilaksanakan dengan jalan mensinergikan berbagai potensi yang ada untuk mendorong berkembangnya sistem dan usaha agribisnis yang berdaya saing, berbasis kerakyatan, dan berkelanjutan yang digerakkan oleh masyarakat dan difasilitasi oleh pemerintah (Kabul, 2014). Untuk melakukan pengembangan kawasan agropolitan diperlukan pengembangan komoditas unggulan yang tepat sasaran pada komoditas yang berpotensi dikembangkan (Qadri, 2011; Oksatriandhi \& Santoso, 2014).

Pengembangan agropolitan merupakan salah satu upaya yang dilakukan oleh pemerintah daerah dan pemerintah nasional untuk mempercepat pembangunan perdesaan. Pengembangan agropolitan dilakukan agar masyarakat memiliki sumberdaya ekonomi yang cukup dan otonom untuk merancang serta mengendalikan sendiri langkah proses pembangunannya (Adisasmita, 2008; Sjoraida \& Anwar, 2017).

Allah swt. dalam Al Quran Surah Al-An'am:99 bahwa dari air yang tumpah ke bumi kemudian tumbuh tanaman-tanaman dengan buah yang banyak dan matang sesuai dengan konsep komoditas unggulan dalam pengembangan kawasan Agropolitan, sebagai berikut: 


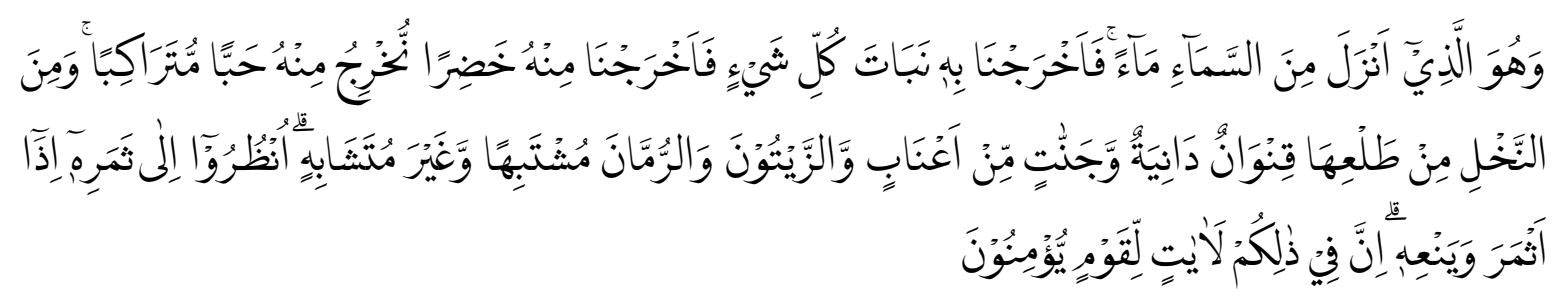

Terjemahnya:

"Dan Dialah yang menurunkan air dari langit, lalu Kami tumbuhkan dengan air itu segala macam tumbuh-tumbuhan, maka Kami keluarkan dari tumbuh-tumbuhan itu tanaman yang menghijau, Kami keluarkan dari tanaman yang menghijau itu butir yang banyak; dan dari mayang kurma, mengurai tangkai-tangkai yang menjulai, dan kebun-kebun anggur, dan (Kami keluarkan pula) zaitun dan delima yang serupa dan yang tidak serupa. Perhatikanlah buahnya pada waktu berbuah, dan menjadi masak. Sungguh, pada yang demikian itu ada tanda-tanda (kekuasaan Allah) bagi orang-orang yang beriman”.

Kabupaten Takalar merupakan salah satu kabupaten yang berada di Provinsi Sulawesi Selatan yang menerapkan konsep pengembangan wilayah agropolitan. Berdasarkan Tim Bappeda (Bappeda, 2012), Pemerintah Kabupaten Takalar dalam Rencana Tata Ruang Wilayah (RTRW) menetapkan wilayah Malolo sebagai kawasan strategis dan cepat tumbuh agropolitan di Kecamatan Polombangkeng Utara untuk periode pengembangan kawasan tahun 2012-2031.

Kebijakan pengembangan agropolitan kawasan Malolo di Takalar belum banyak dilaporkan mampu meningkatkan kesejahteraan masyarakat dan mengoptimalkan potensi sumber daya manusianya. Selain terdapat faktor kesenjangan perekonomian, kurang optimalnya penerapan agropolitan menyebabkan rendahnya kualitas sumberdaya manusia (Arisadi \& Umilia, 2016). Pada kawasan agropolitan sudah terbentuk kelompok tani di setiap desa, namun banyak di antara kelompok tersebut tidak maksimal/tidak aktif. Keadaan sumber daya manusia ini merupakan kekuatan dalam pengembangan kawasan agropolitan (Martadona et al., 2014).

Sebagai upaya untuk mengembangkan kawasan agropolitan Malolo, perlu dilakukan pemetaan komoditas unggulan untuk membantu masyarakat fokus mengembangkan komoditas unggulan yang sesuai dengan kondisi alam dan memiliki nilai ekonomi secara global. Permasalahan pada faktor komoditas unggulan selama ini karena belum ada pemetaan pemanfaatan hasil produksi komoditas unggulan kawasan, sehingga petani cenderung menjual mentah hasil produksinya. Berdasarkan kondisi tersebut, perlu penelitian mengenai analisis pengembangan kawasan agropolitan Malolo melalui pemetaan komoditas unggulan (Sari \& Santoso, 2016).

\section{METODE PENELITIAN}

Pendekatan yang digunakan pada penelitian ini yakni metode deskriptif kuantitatif dan kualitatif dengan menganalisis data primer dan data sekunder. Pengumpulan data primer dilakukan dengan cara observasi lapangan dan wawancara tidak terstruktur. Pengumpulan data sekunder dilakukan dengan cara studi pustaka.

Untuk mengetahui komoditas basis pada kawasan agropolitan Malolo menggunakan analisis location quotient (LQ). Adapun analisisnya sebagai berikut:

$$
L Q=\frac{R i / R t}{N i / N t}
$$


dimana $R i$ adalah nilai produksi komoditas i kecamatan, $R t$ adalah nilai produksi komoditas total kecamatan, $\mathrm{Ni}$ adalah nilai produksi komoditas i kabupaten, dan $\mathrm{Nt}$ adalah nilai produksi komoditas total kabupaten. Kondisi syarat yang digunakan dalam analisis location quotient dalam penetuan komoditas basis, yakni:

- Jika nilai $L Q \geq 1$, maka komoditas tersebut merupakan basis.

- Jika nilai LQ $<1$, maka komoditas tersebut merupakan non basis.

Untuk mengetahui komoditas unggulan pada kawasan agropolitan Malolo menggunakan analisis shift share (SS). Adapun analisisnya sebagai berikut:

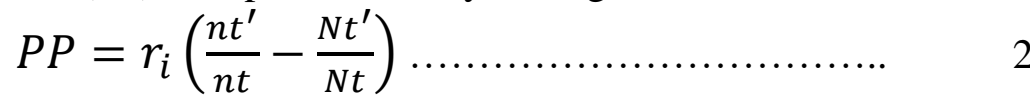

dimana $P P$ adalah pertumbuhan proporsional, $r_{i}$ adalah nilai produksi komoditas i kawasan tahun awal, $n t^{\prime}$ adalah nilai produksi komoditas i kabupaten tahun akhir, $n t$ adalah nilai produksi sumber daya i kabupaten tahun awal, $N t^{\prime}$ adalah nilai produksi total kabupaten tahun akhir, dan $N t$ adalah nilai produksi total kabupaten tahun awal. Untuk mengetahui pertumbuhan pangsa wilayah $(P P W)$ dapat menggunakan persamaan 3:

$$
P P W=r_{i}\left(\frac{r_{i}^{\prime}}{r_{i}}-\frac{n t^{\prime}}{n t}\right)
$$

dimana $r_{i}^{\prime}$ adalah nilai produksi komoditas i kawasan tahun akhir, dan $r_{i}$ adalah nilai produksi komoditas i kawasan tahun awal.

$$
P B=P P+P P W
$$

dimana $P B$ adalah pertumbuhan bersih. Kondisi syarat yang digunakan dalam menentukan komoditas unggulan, yakni:

- Jika PP > 0, maka komoditas i pada kawasan j pertumbuhannya cepat

- Jika PP <0, maka komoditas i pada kawasan j pertumbuhannya lambat

- Jika PPW > 0, maka kawasan j memiliki daya saing yang baik di komoditas i dibandingkan dengan kecamatan lain

- Jika PPW < 0, maka komoditas i pada kawasan j tidak dapat bersaing dengan baik apabila dibandingkan dengan kecamatan lain

- Jika PB > 0, maka pertumbuhan komoditas i pada kawasan $\mathrm{j}$ termasuk kelompok progresif (maju)

- Jika PB < 0, maka pertumbuhan komoditas i pada kawasan j termasuk lamban.

Untuk mengetahui komoditas unggulan di kawasan, maka dilakukan perbandingan nilai LQ dan PB pada tipologi Klassen. Apabila komoditas tertentu memiliki nilai LQ > 1 dan $\mathrm{PB}>0$ maka komoditas tersebut tergolong komoditas unggulan. Berikut adalah matriks jenis komoditas berdasarkan nilai LQ dan PB dapat dilihat pada Tabel 1.

Tabel 1. Klasifikasi komoditas berdasarkan gabungan LQ dan SS.

\begin{tabular}{lcc}
\hline Kriteria & LQ $>\mathbf{1}$ & LQ $<\mathbf{1}$ \\
\hline $\mathrm{PB}>0$ & Komoditas Unggulan & Komoditas Andalan \\
$\mathrm{PB}<0$ & Komoditas Prospektif & Komoditas Tertinggal \\
\hline
\end{tabular}

Untuk pemetaan komoditas basis dan komoditas unggulan menggunakan hasil analisis Location Quotient dan hasil integrasi Analisis LQ dan SS yang digambarkan dengan pemetaan menggunakan aplikasi Sistem Informasi Geografis (GIS) (Susanto, 2016). Kriteria pertama yang menjadi persyaratan penting apabila ingin mengembangkan kawasan agropolitan adalah memiliki komoditas dan produk olahan pertanian unggulan. Komoditas unggulan yang dimaksud adalah tanaman pangan (jagung, padi), hortikultura (sayur-sayuran, buah-buahan, bunga), perkebunan (kakao, sawit, kopi), perikanan darat atau laut (udang dan berbagai jenis ikan) dan peternakan (sapi, kerbau) (Sjoraida \& Anwar, 2017). Jenis 
komoditas yang memberikan informasi tentang produk unggulan, potensial dan sebagainya yang nantinya lebih fokus untuk pengembangan di masa mendatang (Susanto, 2014). Adapun kerangka konsep penelitian disajikan pada Gambar 1.

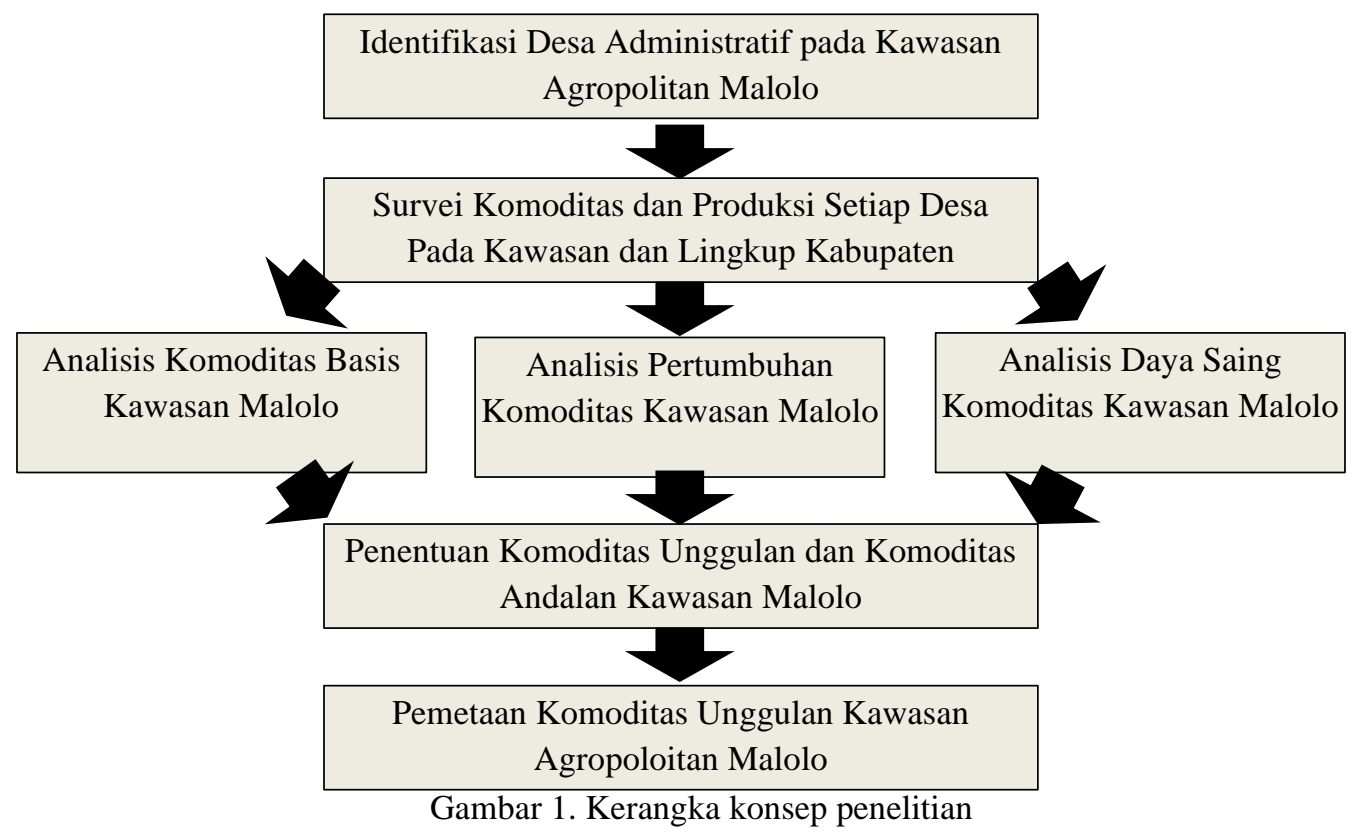

\section{HASIL DAN PEMBAHASAN}

Komoditas unggulan adalah sektor perekonomian yang mempunyai nilai sangat dominan serta mempunyai keunggulan dalam kontribusi produksi, baik sektoral maupun total, daya persebaran dan derajat yang kuat, serta mempunyai basis ekonomi yang kuat. Berbagai program pertanian untuk pengembangan komoditas dapat dilaksanakan pada lahanlahan yang sesuai secara fisik dan kondisi agroklimat yang ada di wilayah/kawasan perencanaan sebagai suatu kebijakan pemerintah. Berikut gambar peta komoditi unggulan padi di kawasan agropolitan Malolo Kabupaten Takalar.
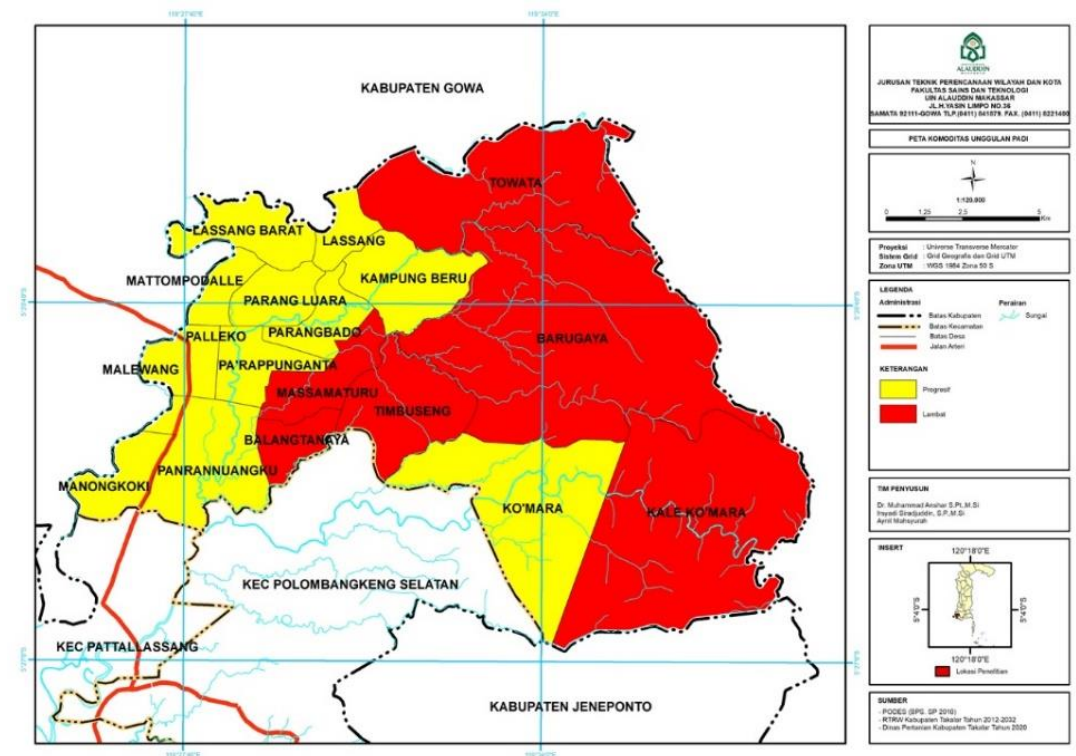

Gambar 2. Peta komoditas unggulan padi kawasan agropolitan Malolo Kecamatan Polongbangkeng Utara Kabupaten Takalar 
Wilayah desa/kelurahan yang termasuk tipologi lambat komoditi unggulan padi di kawasan agropolitan Malolo Kabupaten Takalar yakni desa/kelurahan Towata, Barugaya, Kale Ko'mara, Timbuseng, Massamaturu, Balangtanaya Sedangkan yang termasuk wilayah desa/kelurahan yang termasuk tipologi progresif yakni Lassang Barat, Lassang, Mattompodalle, Kampung Beru, Parang Luara, Palleko, Parangbado, Pa'rappunganta, Panrannuangku, Manongkoki, Ko'mara, dan Malewang.

Sumber daya lahan dapat dimanfaatkan kesuburannya untuk menanam berbagai tanaman sesuai dengan kesuburan lahan, elevasi, dan iklim yang melingkupinya. Sumber daya lahan ini dapat dipergunakan untuk memproduksi dan memperbaharui komoditas nabati maupun untuk memproduksi dan memperbaharui komoditas hewani. Berikut gambar peta komoditi unggulan jagung di kawasan agropolitan Malolo Kabupaten Takalar.
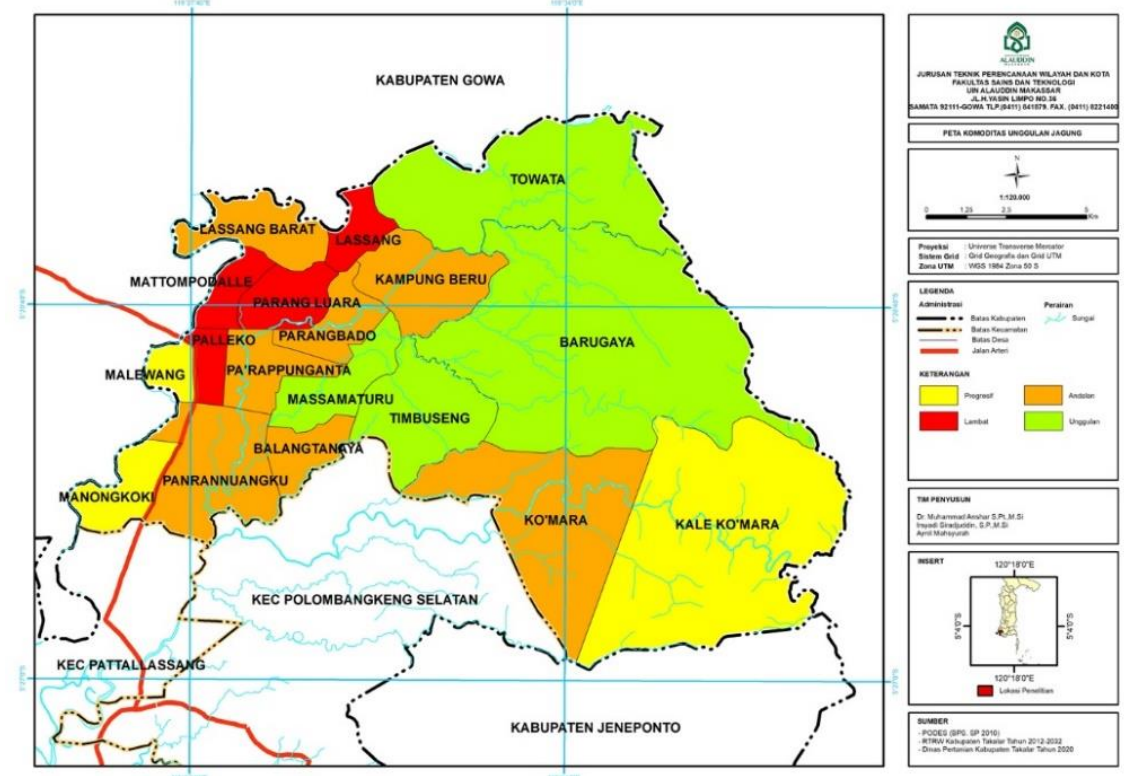

Gambar 3. Peta komoditas unggulan jagung kawasan agropolitan Malolo Kecamatan Polongbangkeng Utara Kabupaten Takalar

Wilayah desa/kelurahan yang termasuk tipologi progresif komoditi jagung di kawasan agropolitan Malolo Kabupaten Takalar yakni Kale Ko'mara, Manongkoki, Malewanog dan tipologi lambat yakni desa/kelurahan Lassang, Mattompodalle, Palleko, Parang Luara. Untuk wilayah desa/kelurahan tipologi andalan komoditi jagung yakni Ko'mara, BalangTanaya, Panrannuangku, Pa'rappunganta, Parangbado, Kampung Beru serta Lassang Barat dan wilayah desa/kelurahan tipologi unggulan yakni Towata, Barugaya, Timbuseng dan Massamaturu.

Potensi lokasi dapat juga dilihat dari kenyataan bahwa kawasan budidaya merupakan kombinasi berbagai kegiatan manusia yang saling berkaitan. Kawasan budidaya akan menampilkan struktur tata ruang sebagai gambaran adanya potensi lokasi dari keseluruhan kinerja wilayah. Berikut gambar peta komoditi unggulan kacang hijau di kawasan agropolitan Malolo Kabupaten Takalar. 

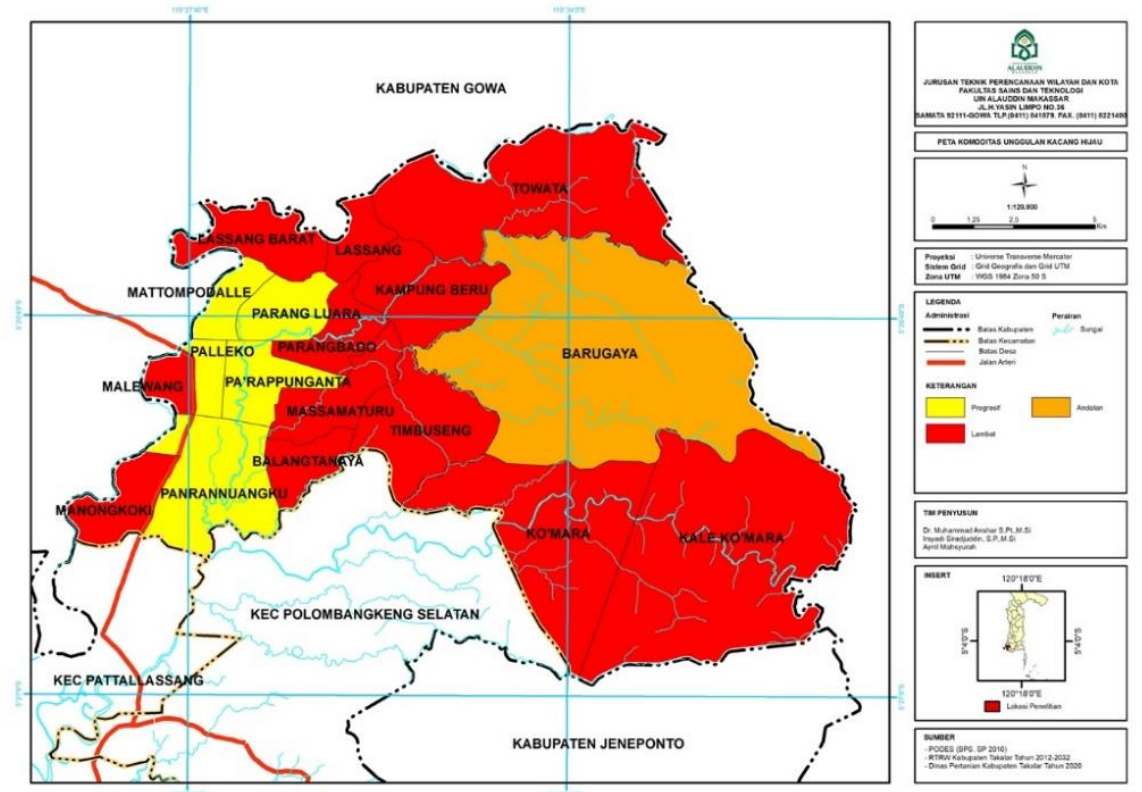

Gambar 4. Peta komoditas unggulan kacang hijau kawasan agropolitan Malolo Kecamatan Polongbangkeng Utara Kabupaten Takalar.

Wilayah desa/kelurahan yang termasuk tipologi progresif komoditi kacang hijau di Kawasan Agropolitan Malolo Kabupaten Takalar yakni Mattompodalle, Parang Luara, Palleko, Pa'rappunganta, Panrannuangku sedangkan desa/kelurahan yang termasuk kategori tipologi yaitu Barugaya dan wilayah desa/kelurahan yang termasuk kategori tipologi yakni Kale Ko'mara, Manongkoki, Malewang, Lassang, Ko'mara, BalangTanaya,Parangbado, Kampung Beru serta Lassang Barat, Towata, Timbuseng dan Massamaturu.

Komoditas potensial adalah sektor atau kegiatan ekonomi yang mempunyai potensi, kinerja, dan prospek yang lebih baik dibandingkan sektor lainnya sehingga diharapkan mampu menggerakkan kegiatan usaha ekonomi dan dapat tercipta kemandirian pembangunan wilayah atau kawasan. Berikut gambar peta komoditi unggulan ubi kayu di kawasan agropolitan Malolo Kabupaten Takalar.

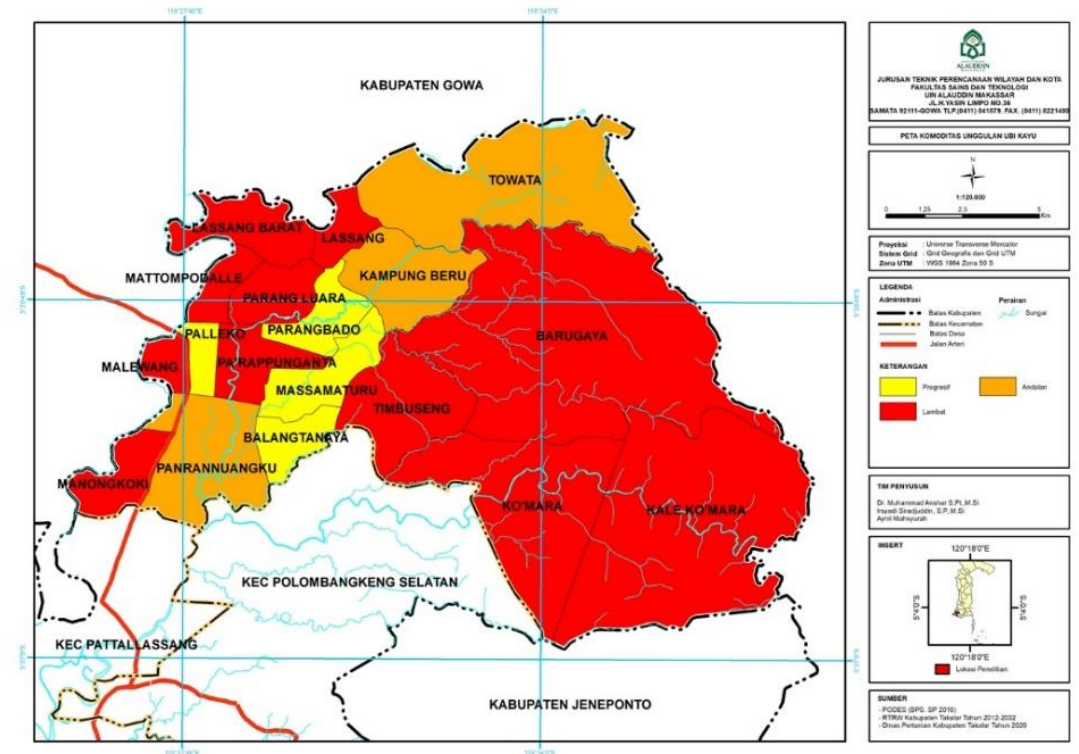

Gambar 5. Peta komoditas unggulan ubi kayu kawasan agropolitan Malolo Kecamatan Polongbangkeng Utara Kabupaten Takalar. 
Wilayah desa/kelurahan yang termasuk tipologi progresif komoditi ubi kayu di kawasan agropolitan Malolo Kabupaten Takalar yakni Palleko, Massamaturu, BalangTanaya, Parangbado dan desa /kelurahan yang termasuk tipologi andalan yakni Towata, Kampung Beru serta Panrannuangku sedangkan wilayah desa/kelurahan dalam kategori lambat yakni Kale Ko'mara, Manongkoki, Malewang,Lassang, Mattompodalle, Parang Luara, Ko'mara, Pa'rappunganta, dan Lassang Barat.

Sektor unggulan dapat dikelompokkan menjadi dua, yaitu sektor unggulan yang mempunyai nilai yang sangat dominan, yang dapat diintrepretasi sebagai sektor perekonomian yang mempunyai keunggulan dalam kontribusi produksi, baik sektoral maupun total, daya persebaran dan derajat kepekaan yang kuat, serta mempunyai basis ekonomi yang kuat dan sektor potensial, merupakan sektor-sektor yang tidak dominan sehingga masih bisa dikembangkan. Berikut gambar peta komoditi unggulan ubi jalar di kawasan agropolitan Malolo Kabupaten Takalar.

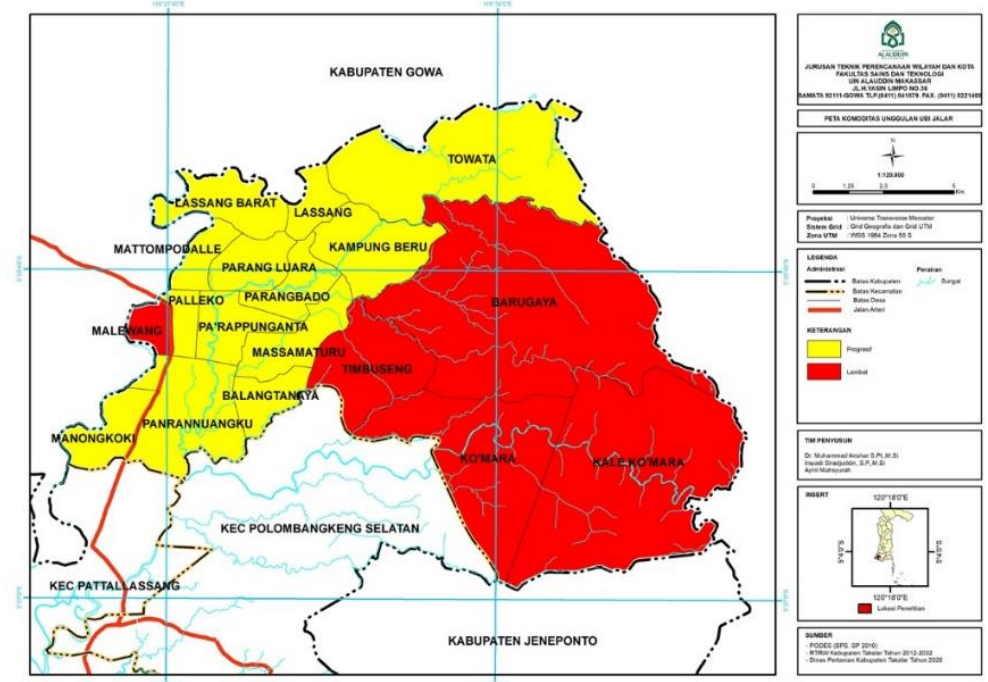

Gambar 6. Peta komoditas unggulan ubi jalar kawasan agropolitan Malolo Kecamatan Polongbangkeng Utara Kabupaten Takalar

Wilayah desa/kelurahan yang termasuk tipologi lambat komoditi ubi jalar di kawasan agropolitan Malolo Kabupaten Takalar yakni Ko'mara, Barugaya, Timbuseng, Kale Ko'mara dan Malewang sedangkan yang termasuk tipologi progresif yakni desa/kelurahan Manongkoki, Lassang, Mattompodalle, Palleko, Parang Luara Balangtanaya, Panrannuangku, Pa'rappunganta, Parangbado, Kampung Beru serta Lassang Barat Towata, dan Massamaturu.

\section{KESIMPULAN}

Komoditas pertanian yang merupakan komoditas basis pada kawasan agropolitan Malolo yaitu: a) Komoditi padi yang berada pada desa/kelurahan Palleko, Parangbado, Mannongkoki, Panrannuangku, Malewang, Pa'rappunganta, Kampung Beru, Lassang, Lassang Barat, Mattompodalle, Parang Luara, Ko'mara, Massamaturu; b) Komoditi jagung yakni pada desa/kelurahan Mannongkoki, Malewang, Massamaturu, Kale ko'mara,Timbuseng, Barugaya, Towata; c) Komoditi kacang hijau yakni pada desa/kelurahan Parang Luara, Pa'rappunganta, Palleko, Panrannuangku,Mattompodalle; d) Komoditi ubi kayu pada desa/kelurahan yakni desa/kelurahan Parang Luara, Pa'rappunganta, Palleko, Massamaturu Balangtanaya; dan e) Komoditi ubi jalar, wilayah desa/kelurahan yang menjadi basis komoditi ubi jalar di kawasan agropolitan Malolo Kabupaten Takalar 
yakni desa/kelurahan Lassang Barat, Lassang, Mattompodalle, Kampung Beru, Parang Luara, Palleko, Parangbado, Pa'rappunganta, Massamaturu, Balangtanaya, Panrannuangku, Manongkoki. Komoditas basis yang dapat dijadikan komoditas unggulan pada kawasan agropolitan Malolo yakni komoditi jagung yang tersebar di Desa dan Keluarahan yakni Towata, Barugaya, Timbuseng dan Massamaturu.

\section{DAFTAR PUSTAKA}

Adisasmita, R. (2008). Pembangunan Pedesaan dan Perkotaan. Yogyakarta: Graha ilmu.

Arisadi, E. D., \& Umilia, E. (2016). Arahan Pengembangan Kawasan Sumbing Kabupaten Magelang sebagai agropolitan. Jurnal Teknik ITS, 5(1), 12-17.

Baladina, N., Anindita, R., Isaskar, R., \& Sukardi. (2013). Identifikasi potensi komoditi pertanian unggulan dalam penerapan konsep agropolitan di Kecamatan Poncokusumo Kabupaten Malang. Agrise XIII 1, 30-41.

Bappeda Takalar. (2012). Rencana Tata Ruang Wilayah Kabupaten Takalar Tahun 2012-2031. Takalar: Badan Perencanaan Pembangunan Daerah Kabupaten Takalar.

Kabul, M. A. (2014). Agropolitan Teori dan Aplikasi. Yogyakarta: Graha Ilmu.

Kementerian Agama Republik Indonesia. (2002). Al Qur'an dan Terjemahannya. Jakarta: Kementerian Agama Republik Indonesia.

Martadona, I., Purnamadewi, Y. L., \& Najib, M. (2014). Strategi pengembangan kawasan agropolitan berbasis tanaman pangan di Kota Padang. Tata Loka, 16(4), 234-244.

Oksatriandhi, B., \& Santoso, E. B. (2014). Identifikasi komoditas unggulan di kawasan agropolitan Kabupaten Pasaman. Jurnal Teknik Pomits, 3(1), 8-11.

Qadri, F. (2011). Konsep Perencanaan dan Pengembangan Wilayah. Yogyakarta: Liberty.

Sari, D. A. W., \& Santoso, E. B. (2016). Faktor-faktor yang mempengaruhi pengembangan komoditas unggulan hortikultura di kawasan agropolitan Ngawasondat Kabupaten Kediri. Jurnal Teknik ITS, 5(1), 64-69.

Setianto, P., \& Susilowati, I. (2014). Komoditas perkebunan unggulan yang berbasis pada pengembangan wilayah kecamatan di Kabupaten Banjarnegara Provinsi Jawa Tengah. Jurnal Wilayah dan Lingkungan, 2(2), 143-156.

Sjoraida, D. F., \& Anwar, R. K. (2017). Pengembangan Sistem Perekonomian Melalui Informasi Pembangunan Dengan Masyarakat di Desa Agropolitan. Bandung: UNPAD Press.

Susanto, A., Kharis, A., \& Khotimah, T. (2016). Sistem Informasi Geografis Pemetaan Lahan Pertanian dan Komoditi Hasil Panen Kabupaten Kudus. Jurnal Informatika, 10(2), 1233-1243.

Susanto, H. (2014). Kajian Komoditas Unggulan, Andalan, dan Potensial di Kabupaten Grobogan. Jurnal of Rural and Development, V(1), 63-80. 